\title{
The Factors affecting Knowledge Sharing at the Iranian Ministry of Sports
}

\author{
${ }^{1}$ Rahmatollah Gholipour Souteh ${ }^{*},{ }^{2}$ Mohammad Reza Esmaeili, ${ }^{3}$ Habib Honari, \\ ${ }^{2}$ Mohammad Hoseein Ghorbani
}

${ }^{1}$ Department of Governmental Administration, Management Faculty, University of Tehran, Tehran, Iran. ${ }^{2}$ Sport Management Department, Sport Science Research Institute, Tehran, Iran. ${ }^{3}$ Department of Sport Management, Faculty of Sport Sciences, Allameh Tabataba'i University, Tehran, Iran.

\begin{abstract}
Background. Knowledge today is a strategic factor in achieving a sustainable competitive advantage for power in an organization, but merely having knowledge only as an asset does not create value. The sharing and dissemination of knowledge with other members within and outside the organization will provide a space for the creation of new and valuable knowledge assets. Objectives. The aim of this study was to identify and prioritize factors affecting knowledge sharing and dissemination in Iran's ministry of youth and sports. Methods. This study employed the qualitative research method. The study population included all managers, advisers, and experts of the ministry and faculty members informed in the field of knowledge management within the ministry. In the first stage, purposive sampling based on theoretical 1 approach and 19 semi-structured interviews were conducted. Using coding method seven main factors were detected by MAXQDA software. The next step was to prioritize and interpretive structural modeling and the opinion of eight experts and academic professors was used. Results. After analyzing the data, factors affecting knowledge sharing were put into 5 levels. Leadership factors were placed at the bottom of the model and the individual factors placed at the highest level. Conclusion. The insight that this model offers can help in the success and effectiveness of KM activities in this ministry.
\end{abstract}

KEY WORDS: Knowledge Management, Structural Interpretative Modeling, Leadership and Individual Factors, Sports.

\section{INTRODUCTION}

One of the key factors of knowledge economy is that organizations need to manage organizational knowledge. However, reviewing the related literature indicates that this issue has not been given due consideration in sport organizations (1). Sport organizations, just like other organizations, need to achieve success in acquiring, storing, sharing, managing, and controlling their organizational knowledge to reduce uncertainty about the results of their decisions and administrative procedures as well as coordinating and facilitating the execution of their goals and strategic measures (2). Workplace tools and structures that efficiently facilitate the sharing and creation of knowledge are important to the survival and growth of national sport organizations (3).

Iran's Ministry of Youth and Sports as the organization responsible for the youth affairs and

*. Corresponding Author:

Rahmatollah Gholipour Souteh

E-mail: rgholipor@ut.ac.ir 
sports, increasingly needs to pay more attention to knowledge management and applying the intellectual capitals as well as its individual and organizational knowledge for various reasons. One of these reasons outlined is responsible for the existing intense and increasing competition among the sport organizations in both national and international levels. Moreover, since this organization is governmental in nature, the withdrawal of the knowledge forces are of a high level; we can see numerous examples of transfer for managers, deputies, advisors, and coaches. Certainly these individual have acquired a great deal of experience and knowledge during their career in various positions and responsibilities in these organizations. When they leave the organization, this knowledge also goes out of the organization as well; this will impose high cost for the organization. On the other hand, the sports environment is faced with a lot of changes due to various reasons including globalization, changes in expectations and needs of the beneficiaries (staffs, citizens, athletes, coaches, etc.), the emergence of new sports, the ongoing changes of rules, methods and techniques, etc. In such an environment with a lot of changes, knowledge management is recognized as the best method for dealing with ongoing changes (4-6).

The review of the related literature in the sport organizations indicates the importance of knowledge management in these organizations. $\mathrm{KM}$ is introduced as best practice for sport organizations that can transform their performance. (3) Schenk et al. (2015) has emphasized the importance of knowledge management in the sport events and has offered knowledge management model of Canada Games (7). Halbwirth and Toohey (2001) state that since people's cultures, countries' rules, and technological needs are different in the cities and countries hosting the Olympic games, the effective application of a knowledge management system is one of the critical needs of the organizing committees of the Olympic games. The organizing committee of the Sydney Olympic Games enjoyed such a system (2).

$\mathrm{KM}$ process consists of four activities; knowledge production and development, knowledge recording and storing, knowledge transfer and sharing, and knowledge application (8). $\mathrm{KM}$ is a process where organizations start creating values on intellectual and knowledge capitals. Often, the creation of value requires the sharing of knowledge between employees, organizational units or even other organizations (9). Undoubtedly knowledge sharing process is one of the key procedures of knowledge management $(10,11)$. Due to global competition in recent years, KS has been identified as a basic facilitator for effective KM which can assist in optimizing business goals (12). Sharing knowledge is one of the' key contributions of employee's to amplify organizational knowledge, leading to high performance of the organization (13). KS gets special attention because knowledge as an asset increases in value with use (14). Many organizations have realized the advantages and benefits of sharing information and knowledge within the organization (15). Knowledge that is created in the human mind, in general has little value to the enterprise unless it is shared (16). The biggest value of knowledge that can be achieved in an organization is when it is shared because it can lead to an increase in job performance and facilitate new knowledge creation (17).

Knowledge sharing has outstanding and distinct aspects; recognized material capitals are subject to reduced profitability. However, when the staffs share their knowledge, it will have an increased value. Since the potential benefits of an organization can be increased through knowledge sharing, most of the organizations invest a great deal of time and money on knowledge management; this is an innovative measure taken in the process of developing knowledge management systems. However, in spite of these investments, the outcome of failed knowledge sharing is estimated as millions of dollars that is inevitably undertaken by the organizations (18).

According the importance and the expected benefits of knowledge sharing, different organizations have sought to identify the factors that influence the facilitation of knowledge sharing and various studies have been done in this area (19-22). However, in Iran's sports organizations, especially the Ministry of Youth and Sports, due to its special features, no noticeable finding has been made on a why and how factors affect knowledge sharing. Thus, the present study aims at data mining of the factors affecting knowledge sharing in the Ministry of 
Youth and Sports through taking a heuristic approach.

\section{MATERIALS AND METHODS}

Research design. In view of the purpose of this research, qualitative method was utilized.

Participants. The statistical population included all managers, advisers and experts of the Ministry of Youth and Sports and faculty members informed in the field of knowledge management in the ministry. Purposeful sampling method was used based on theoretical approach, and data collection continued until theoretical saturation.

Data Collection. In the first stage, to identify the factors affecting knowledge sharing, content analysis was used (through study papers, documents and interviewing tools). Using coding method 7 main factors were detected by MAXQDA software. In the next step, the interpretive structural modeling approach (ISM) was used to determine the sequence and the relationship between identified elements from the viewpoint of eight experts and academic professors.

Statistical Analysis. In summary, in this study, the following steps were taken to analyze collated data and achieve the main goal of the research:

1. Identification and determination of decisionmaking criteria.
2. Formation of a structural self-interaction matrix (SSIM).

3. Formation of a reachability matrix from the SSIM.

4. Determination of relationships and leveling between factors.

5. Drawing of a network of interactions between factors.

\section{RESULTS}

In this study, in order to identify the factors affecting knowledge sharing, after carefully studying the books, articles, and documents, semi-structured interviews were conducted with 19 experts, directors general, deputies, minister's advisors, and faculty members. After every interview, the content was typed and the primary analysis and coding were conducted right after the interview through applying constant comparison. Through applying the software, 218 primary codes were created from all the interviews. Then, the primary codes (concepts) were reduced to 14 secondary codes; this was done based on conceptual and meaningful relationship and similarity. Finally, based on the secondary codes, 7 main items were created. In Table 1; we can see a sample of how the main factors are formed.

Table 1. The results of coding and the formation of "individual factors" item

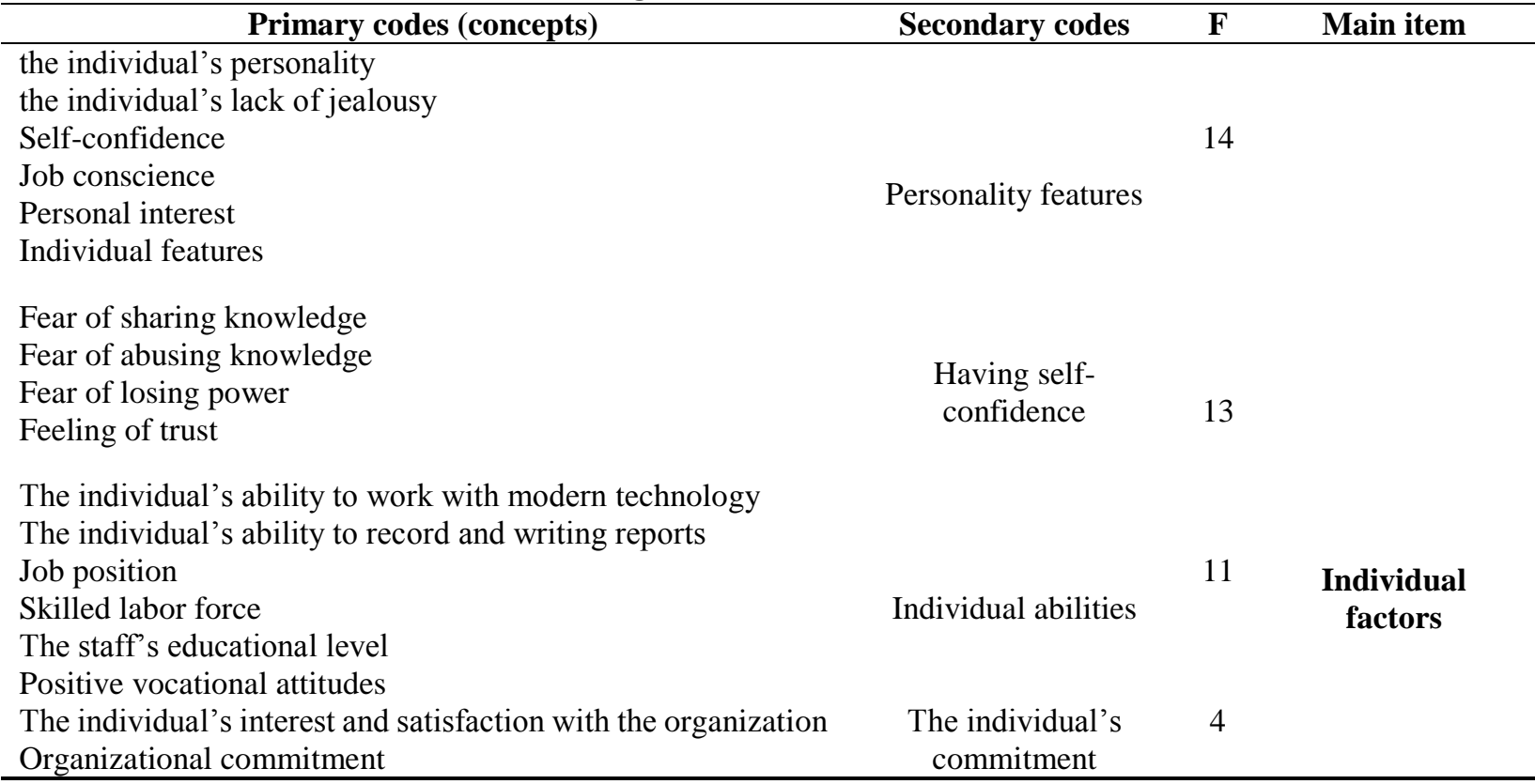


In the second step, after identifying the effective factors, questionnaire were provided to university professors who were both scientifically and practically specialized in this field. Using the comments of eight participants, interpretive structural modeling was carried out. The output and answers of experts are shown in Table 2. To form this matrix, the following four symbols were used to determine the conceptual relation between variables:

$\mathrm{V}$ for the relation from $i$ (row) to $j$ (Column) but not in opposite directions; A for the relation from $j$ to $i$ but not in opposite directions; $\mathrm{X}$ for both direction relations from $i$ to $j$ and $j$ to $i$; and $\mathrm{O}$ if the relation between the factors does not appear valid.

Table 2. Structural self-interaction matrix (SSIM)

\begin{tabular}{clllllll}
\hline Factor number & \multicolumn{1}{c}{ Factor Description } & $\mathbf{7}$ & $\mathbf{6}$ & $\mathbf{5}$ & $\mathbf{4}$ & $\mathbf{3}$ & $\mathbf{2}$ \\
\hline 1 & Leadership Factors & V & V & V & V & V & V \\
2 & Organizational culture & O & V & A & X & A & \\
3 & KM strategic plan & V & O & V & V & & \\
4 & Organizational structure & O & V & O & & & \\
5 & Human resources management & O & V & & & & \\
6 & Individual factors & A & & & & & \\
7 & Information Technology & & & & & & \\
\hline
\end{tabular}

Then The SSIM has been converted into a binary matrix, called the initial reachability matrix (see Table 3 ) by substituting $\mathrm{V}, \mathrm{A}, \mathrm{X}$ and $\mathrm{O}$ by 1 and 0 as per given case.

Table 3. Initial reachability matrix

\begin{tabular}{clcccccccc}
\hline Factor number & \multicolumn{1}{c}{ Factor Description } & $\mathbf{1}$ & $\mathbf{2}$ & $\mathbf{3}$ & $\mathbf{4}$ & $\mathbf{5}$ & $\mathbf{6}$ & $\mathbf{7}$ & Driving power \\
\hline 1 & Leadership Factors & 1 & 1 & 1 & 1 & 1 & 1 & 1 & 7 \\
2 & Organizational culture & 0 & 1 & 0 & 1 & 0 & 1 & 0 & 3 \\
3 & KM strategic plan & 0 & 1 & 1 & 1 & 1 & 0 & 1 & 5 \\
4 & Organizational structure & 0 & 1 & 0 & 1 & 0 & 1 & 0 & 3 \\
5 & Human resources management & 0 & 1 & 0 & 0 & 1 & 1 & 0 & 3 \\
6 & Individual factors & 0 & 0 & 0 & 0 & 0 & 1 & 0 & 1 \\
7 & Information Technology & 0 & 0 & 0 & 0 & 0 & 1 & 1 & 2 \\
& Dependence power & 1 & 5 & 2 & 4 & 3 & 6 & 3 & \\
\hline
\end{tabular}

In the next step, for determination of relations and leveling of elements, the output set and input set for each element were extracted from the initial reachability matrix. The reachability set consists of the element itself and the other elements which it may help achieve, whereas the antecedent set consists of the element itself and the other elements which may help in achieving it. Then, the intersection of these sets is derived for all the factors. The factors for which the reachability and the intersection sets are the same occupy the top level in the ISM hierarchy. Once the top-level element is identified, it is separated from the other elements. Then, the same process is repeated to find out the elements in the next level. This process is continued until the level of each element is found (see Table 4). Eventually according to the level of each factor, the interpretive structural model of the research was drawn up as shown in Figure 1.

\section{DISCUSSION}

In the present study, the use of Content Analysis Method and ISM was attempted, and the factors affecting knowledge sharing in the Ministry of Sports and Youth were identified and prioritized. Accordingly, the final model of the study consisting of 7 main factors was presented. In this model, leadership factor is at the lowest level, which indicates it is a key factor. According to the participants' views, leadership factor includes components such as top management support and follow up, competence of tap management, senior managers' will and 
commitment, understanding the importance and need for knowledge sharing among top managers, participatory management, encouraging and motivating the personnel, and offering material and spiritual incentives. As long as the top management has not reached this understanding that individual and organizational knowledge is of great importance in this ministry, and it is essential to making it more efficient and productive, one cannot be hopeful for knowledge sharing development. This finding is consistent with the findings of the study conducted by Srivastava et al. (2006) where they indicated that there is a direct relationship between the manager's competence and the staffs' knowledge sharing behavior. They indicated that knowledge sharing is a factor determining the organizational performance, and the organization's manager plays a pivotal role in sharing knowledge within the organization. Thus, the manager's capability triggers and develops knowledge sharing (23). Moreover, Wong (2005) maintains that the support provided by top managers, creating a motivational environment for producing, managing, and sharing knowledge are the most important factors for achieving success in the knowledge management plan (24).

Table 4. Partition of Reachability Matrix

\begin{tabular}{ccccc}
\hline Factor number & Reachability Set & Antecedent Set & Intersection & Level \\
\hline 1 & $1,2,3,4,5,6,7$ & 1 & 1 & 5 \\
2 & $2,4,6$ & $1,2,3,4,5,6$ & 2,4 & 2 \\
3 & $2,3,4,5,7$ & 1,3 & 3 & 4 \\
4 & $2,4,6$ & $1,2,3,4,6$ & 2,4 & 3 \\
5 & $2,5,6$ & $1,4,5,6$ & 5 & 3 \\
6 & 6 & $1,2,4,5,6,7$ & 6 & 1 \\
7 & 6,7 & $1,3,5,7$ & 7 & 2 \\
\hline
\end{tabular}

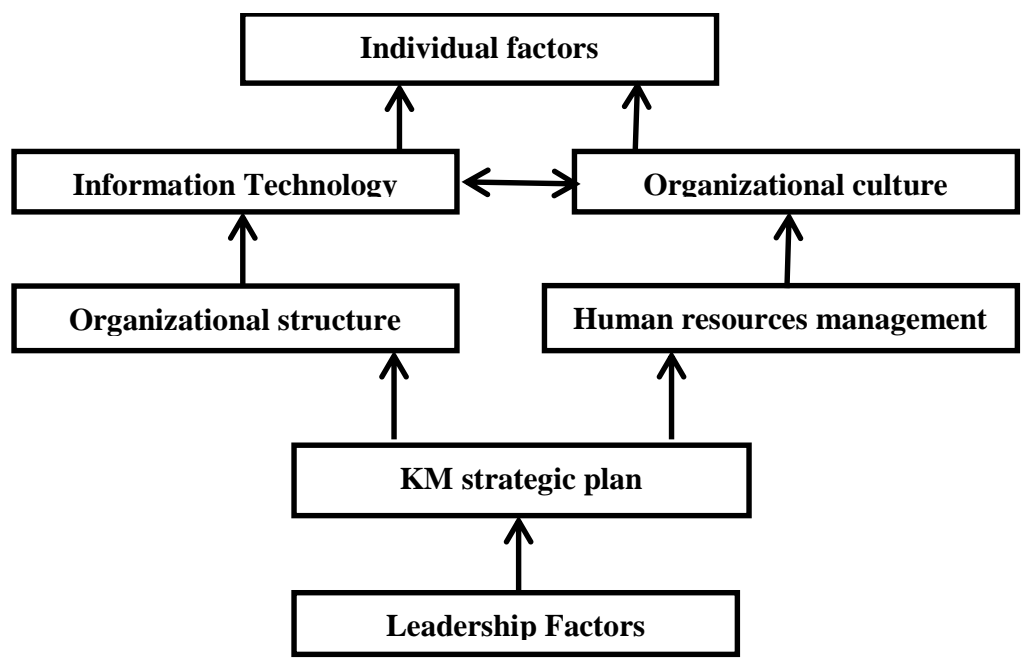

Figure 1. ISM-Model of Factors affecting knowledge sharing

The findings of this study showed that knowledge management strategic plan is one of the key factors affecting knowledge sharing in the ministry, which places it on level 4 of the final model of this research. According to the participants' views, it includes components such as goals, budget, executive plan, and position of knowledge management in the strategic plan of the organization, and knowledge management plan. Like other executive plans, one of the main reasons that help in the development of knowledge sharing in an organization is preparing 
and codification strategic knowledge management plans and linking it with the ministry's strategic plan. Basically, all the activities that have to do with knowledge sharing in the organization reflect a management strategy that values knowledge sharing behavior and encourages it. Some other studies conducted in this regard $(25,26)$ indicate the important role played by the organizational strategy in directing knowledge sharing activities.

In this study, it was discovered that human resources management is one of the key factors affecting knowledge sharing in the ministry placed in level 3 of the final model of this research. In order to pay attention to the human resources of the ministry as valuable resources, it is necessary to identify the individuals' abilities, features, and specialties in the organization and use them in the best way possible. It is necessary to care for meritocracy in selecting and employing individuals. The staffs' performance evaluation, especially with regard to knowledge sharing, must be done constantly in an appropriate way. In doing so, the appropriate criteria need to be identified and determined. They must be offered to individuals, and evaluate the individuals performance based on them. Staff members need to be given feedbacks on the results of the evaluations. Another important component of this item is scheduling and holding training courses. Paying due attention to improved quality and practicality of these courses can be greatly useful. Also investigating if this study showed the organizational structure placed in level 3 of the final model too. According to the participants' views, it includes components such as specialism, designing the workplace, organizational procedures, and the communication among staff. The method for designing the workplace, in such a way that increases communication among the staff, is likely to affect knowledge sharing and circulation in the organization. Moreover, designing the working procedures in such a way that necessitates communication among staff, groups, and working units of the organization and information exchange among these groups and individuals can greatly influence the extent of knowledge sharing in the organization. This finding is consistent with the findings of the study conducted by Noor and Salim (2011) that indicate the effect of designing a workplace and organizational procedures on knowledge sharing (27), O'Dell and Grayson (1998) agree that organizational structures should be designed for flexibility (as opposed to rigidity) to encourage sharing and collaboration across boundaries within the organization and across the supply chain. However, this effect can also be achieved by maintaining the formal hierarchical structure while adding the dimension of flexibility (11).

In this study, it was found that organizational culture is one of the key factors affecting knowledge sharing in this ministry which is placed in level 2 of the final model. This factor includes components such as knowledge-based organizational culture, organizational atmosphere, organizational citizenship behavior, and experience registration culture that affect knowledge sharing in the organization. Creating and developing a workplace in an organization where individuals and organizational groups value knowledge and share their knowledge and experiences $\mathrm{e}$ are of great importance in developing knowledge sharing in the organization; this way they aid both their colleagues and the organization's progress. Various researchers $(27,28)$ have indicated the undeniable role of organizational culture in the extent of knowledge sharing in an organization. Also findings of this study showed that information technology is placed on level 2 of the final model also. The existence of information technology infrastructures and hardware, practical applications, and communication software all affect the extent of knowledge sharing in an organization. Scholars emphasize information technology infrastructure as an element crucial to the extent of knowledge sharing $(29,30)$.

In this study, it was found that the individual factor is placed in the highest level of the final model. It does not mean that this factor is less important. Factors prioritization is only due to a greater understanding and knowing of the relationships between them. According to the participants' views, they include personality features, self-confidence, individual abilities, and the individual's commitment. The individual's personality type, whether introvert or extrovert, his self-confidence, his belief in social activities and teamwork, having trust in colleagues all 
affect the extent of knowledge sharing in the ministry. Moreover, the individual's awareness of knowledge sharing, his ability in recording and transferring his experience and knowledge, his ability to work with modern technologies, and his devotion and commitment to the organization affect the extent of knowledge sharing in this organization as well. These findings are consistent with those of a study conducted by Noor and Salim (2011) based on the influence of individual factors such as knowledge, personality and magnanimity on knowledge sharing behavior; Hussain et al. (2010) based on the influence of employees' individual factors and abilities; Mohaghar et al. (2013) Based on the effect of level of education, training and knowledge-based personality on the success of knowledge management programs $(27,31,32)$.

\section{CONCLUSION}

This study proposed a theoretical framework of the capable factors influencing knowledge sharing in the Iranian ministry of youth and sports that consists of seven capable factors. The results of this study showed that all seven factors identified in this study (Leadership factor, organizational culture, KM strategic plan, organizational structure, human resources management and individual factor) affect knowledge sharing behavior and were prioritized for a better understanding of the relationships between them. This study was conducted for the first time in Iran's sport organizations, especially the Ministry of Youth and Sports. Before this study, factors affecting knowledge sharing in the ministry were not clearly defined, so results of this study can be considered by managers in this ministry. It is believed that this paper will increase the understanding of $\mathrm{KS}$ among employees in the Iranian Ministry of Youth and Sports.

\section{APPLICABLE REMARKS}

- In order to develop knowledge sharing in the Ministry of Youth and Sports, seven factors should be considered including leadership factors, organizational culture, KM strategic plan, organizational structure, human resources management and individual factors as key components, which the relationship between them presented in the final model of the research.

\section{REFERENCES}

1. Salman YW. Knowledge Management Practices in Sport Institutions: Prospects. International Journal of Sports Science. 2016;6(3):96-9.

2. Halbwirth S, Toohey K. The Olympic Games and knowledge management: A case study of the Sydney organising committee of the Olympic Games. European Sport Management Quarterly. 2001;1(2):91-111.

3. O'Reilly NJ, Knight P. Knowledge management best practices in national sport organisations. International Journal of sport management and marketing. 2007;2(3):264-80.

4. Sensuse DI, Cahyaningsih E, Wibowo WC. Knowledge Management: Organizational Culture in Indonesian Government Human Capital Management. Procedia Computer Science. 2015;72:485-94.

5. Mao H, Liu S, Zhang J, Deng Z. Information technology resource, knowledge management capability, and competitive advantage: the moderating role of resource commitment. International Journal of Information Management. 2016;36(6):1062-74.

6. Tseng S-M, Lee P-S. The effect of knowledge management capability and dynamic capability on organizational performance. Journal of Enterprise Information Management. 2014;27(2):158-79.

7. Schenk J, Parent MM, MacDonald D, Proulx Therrien L. The evolution of knowledge management and transfer processes from domestic to international multi-sport events. European Sport Management Quarterly. 2015;15(5):535-54.

8. Mráček P, Mucha M. The Use of Knowledge Management in Marketing Communication of Small and MediumSized Companies. Procedia-Social and Behavioral Sciences. 2015;175:185-92.

9. Bhatt GD. Knowledge management in organizations: examining the interaction between technologies, techniques, and people. Journal of knowledge management. 2001;5(1):68-75.

10. Cranefield J, Yoong P. The role of the translator/interpreter in knowledge transfer environments. Knowledge and Process Management. 2007;14(2):95-103. 
11. O'dell C, Grayson CJ. If only we knew what we know: Identification and transfer of internal best practices. California management review. 1998;40(3):154-74.

12. Singh M, Shankar R, Narain R, Kumar A. Survey of knowledge management practices in Indian manufacturing industries. Journal of Knowledge Management. 2006;10(6):110-28.

13. Trong Tuan L. Knowledge sharing in public organizations: The roles of servant leadership and organizational citizenship behavior. International Journal of Public Administration. 2017;40(4):361-73.

14. Quinn JB, Anderson P, Finkelstein S. Managing professional intellect: making the most of the best. The strategic Management of Intellectual capital. 1998:87-100.

15. Hong Telvin Goh C, Hooper V. Knowledge and information sharing in a closed information environment. Journal of Knowledge Management. 2009;13(2):21-34.

16. Small CT, Sage AP. Knowledge management and knowledge sharing: A review. Information Knowledge Systems Management. 2005;5(3):153-69.

17. Cohen WM, Levinthal DA. Absorptive capacity: A new perspective on learning and innovation. Administrative science quarterly. 1990:128-52.

18. Babcock P. Shedding light on knowledge management. HR magazine. 2004;49(5):46-51.

19. Alam SS, Abdullah Z, Ishak NA, Zain ZM. Assessing knowledge sharing behaviour among employees in SMEs: An empirical study. International Business Research. 2009;2(2):115.

20. Tamjidyamcholo A, Baba MSB, Shuib NLM, Rohani VA. Evaluation model for knowledge sharing in information security professional virtual community. Computers \& Security. 2014;43:19-34.

21. Ismail Al-Alawi A, Yousif Al-Marzooqi N, Fraidoon Mohammed Y. Organizational culture and knowledge sharing: critical success factors. Journal of knowledge management. 2007;11(2):22-42.

22. Lee HS, Hong SA. Factors affecting hospital employees' knowledge sharing intention and behavior, and innovation behavior. Osong public health and research perspectives. 2014;5(3):148-55.

23. Srivastava A, Bartol KM, Locke EA. Empowering leadership in management teams: Effects on knowledge sharing, efficacy, and performance. Academy of management journal. 2006;49(6):1239-51.

24. Yew Wong K. Critical success factors for implementing knowledge management in small and medium enterprises. Industrial Management \& Data Systems. 2005;105(3):261-79.

25. Akhavan P, Imani S. Review and determine the factors influencing knowledge sharing using grounded theory and techniques using Dematel-ISM Fuzzy. Journal of Information Processing and Management. 2016;32(1):93-122.

26. Joshi Y, Parmer S, Chandrawat SS. Knowledge sharing in organizations: modeling the barriers, an interpretive structural modeling approach. management. 2012;2(3).

27. Noor NM, Salim J. Factors influencing employee knowledge sharing capabilities in electronic government agencies in Malaysia. International Journal of Computer Science. 2011;8(4):106-14.

28. Kathiravelu SR. Factors influencing knowledge sharing behavior (KSB) among employees of public services in Malaysia. International Journal of Academic Research in Economics and Management Sciences. 2013;2(3):107.

29. Pérez-López S, Alegre J. Information technology competency, knowledge processes and firm performance. Industrial Management \& Data Systems. 2012;112(4):644-62.

30. Soto-Acosta P, Popa S, Palacios-Marqués D. Social web knowledge sharing and innovation performance in knowledge-intensive manufacturing SMEs. The Journal of Technology Transfer. 2017;42(2):425-40.

31. Mohaghar A, Shami Zanjani M, Nouri M. Identification and Ranking of Critical Success Factors of Knowledge Management Using Fuzzy Quality Function Deployment Approach: A Case Study. Journal of Information Processing and Management. 2014;28(4):1037-68.

32. Hussain I, Ahmed S, Si S. Personal Knowledge Abilities and Knowledge Management Success. Journal of Information \& Knowledge Management. 2010;9(04):319-27. 